\title{
Endobronchial low-grade MALT lymphoma causing unilateral hypertranslucency
}

\author{
A.E. Erbaycu1, I. Karasu1, F.G. Özdemirkıran², \\ N. Yücel ${ }^{3}$, A. Özsöz'1, O. Bilgir²
}

ABSTRACT: Endobronchial low-grade MALT lymphoma causing unilateral hypertranslucency. A.E. Erbaycu, I. Karasu, F.G. Özdemirkıran, N. Yücel, A. Özsöz, O. Bilgir. Mucosa-associated lymphoid tissue-derived lymphoma (MALT lymphoma) arises not only from the stomach but also from various non-gastrointestinal sites. A thirty two year old woman, suffering from breathlessness for one year, had been treated for bronchial asthma. A chest radiograph showed a mediastinum and heart transposition to the right side and emphysema of the left lung. In the thorax spiral tomography, a mass narrowing left main bronchi, five centimeters in length from the carina, was seen. A fiberoptic bronchoscopy revealed millimetric polypoid lesions those nearly totally obstructed the left main bronchi. The bronchoscopic biopsy showed a diagnosis of MALT lymphoma. She was seen for check-ups following chemotherapy but no further treatment has been carried out.

Monaldi Arch Chest Dis 2004; 61: 4, 237-240.

Keywords: MALT lymphoma, endobronchial lymphoma, unilateral emphysema.

1 Department of Chest Diseases, Izmir Chest Diseases and Surgery Centre.

2 SSK Bozyaka Education Hospital, Department of Hematology.

3 Department of Pathology, Izmir Chest Diseases and Surgery Centre, Izmir, Turkey.

Correspondence: Dr Ahmet Emin Erbaycu; Izmir Gogus Hastalıklarl Hastanesi; Yenisehir, Izmir, 35110, Turkey; e-mail: drerbaycu@yahoo.com

\section{Introduction}

Mucosa-associated lymphoid tissue derived lymphoma (MALT lymphoma), first described in 1983 by Isaacson and Wright, was recognised only in 1994 as a distinct entity of lymphoma in the revised European-American lymphoma classification among the marginal zone B-lymphomas as well as in the more recent classification proposed by the World Health Organization. This entity represents about $8 \%$ of all non-Hodgkin's lymphomas and was recently re-classified as "extranodal marginal zone lymphomas of MALT type". They arise not only from the stomach but also from various non-gastrointestinal sites $[1,2,3]$.

Primary pulmonary lymphoma is rare and accounts for $1 \%$ of all lung malignancies and $<10 \%$ of all extranodal lymphomas. Lymphomas affecting the lung are divided into three categories: diffuse large B-cell lymphoma, lymphomatoid granulomatosis and MALT/BALT (mucosa / bronchus associated lymphoid tissue) lymphoma. The most common is MALT lymphoma accounting for $<1 \%$ of all lymphomas $[1,4,5]$.

In this report; a case of MALT lymphoma with single lung involvement mimicking various pulmonary disorders, is presented.

\section{Case Report}

A 32 year old woman was admitted to hospital with dyspnoa on exertion for one year. She had been treated with bronchodilators as a patient with bronchial asthma. Neither she nor her family showed any previous medical history of this condition. She did not have a habit of cigarette smoking, alcohol or any drug consumption and in general, she was in very good health. On physical examination, vital parameters were normal. Auscultation was normal on the right hemithorax where the breath sound was decreased on the left side, and other systemic examinations were normal.

Laboratory results showed that leucocyte count was $11.600 / \mathrm{mm}^{3}$, while the other results of blood counts and biochemical tests were within normal ranges. Arterial blood gas analysis was: pH: $7.38, \mathrm{paO}_{2}: 77.8 \mathrm{mmHg}, \mathrm{paCO}_{2}: 37.6 \mathrm{mmHg}$, $\mathrm{HCO}_{3}: 19.4 \mathrm{mmol} / \mathrm{L}$; spirometry showed a $\mathrm{FEV}_{1}$ : $1.74 \mathrm{~L}(65 \%$ of predicted value), FVC: $1.861 \mathrm{~L}$ $(60 \%)$ and $\mathrm{FEV}_{1} / \mathrm{FVC}: 93 \%$.

The chest radiograph showed (figure 1); transposition of mediastinum and heart to the right side, hypertranslucency on the left lung. A six direction static lung perfusion scanned using a $5 \mathrm{mCi}$ Tc$99 \mathrm{~m}$ macro-aggregates of albumin and lung ventilation scanned using a $20 \mathrm{mCi}$ Tc-99m DTPA revealed no perfusion and ventilation on the left lung. A thorax spiral computed tomography (CT) showed a mass originating from the left distal part of the trachea, narrowing the main left bronchi completely. The upper lobe, lingula and lower lobe bronchi were free, but emphysema was seen on the left lung parenchyma. In multi-planar reconstruction cross section; it was seen that a mass caused 


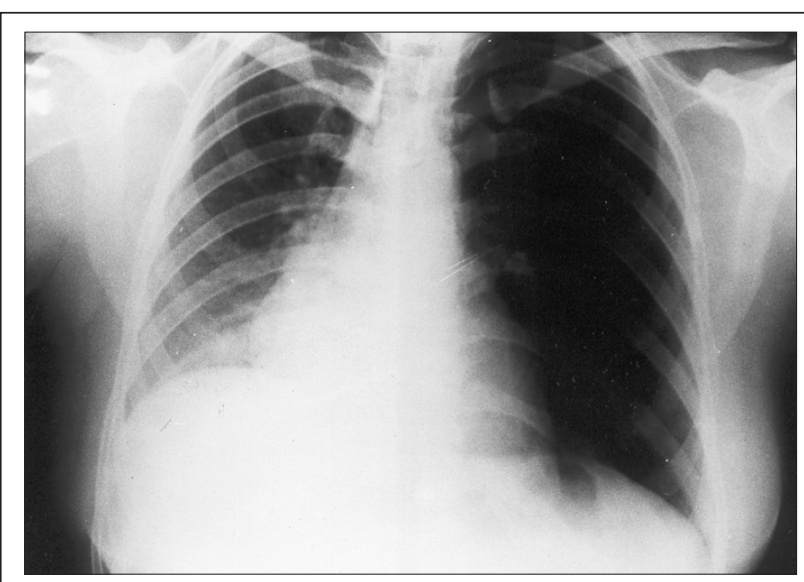

Fig. 1. - Chest-X-ray showing unilateral hyperlucency, emphysema of the left lung and mediastinum and heart transposition to the right side.

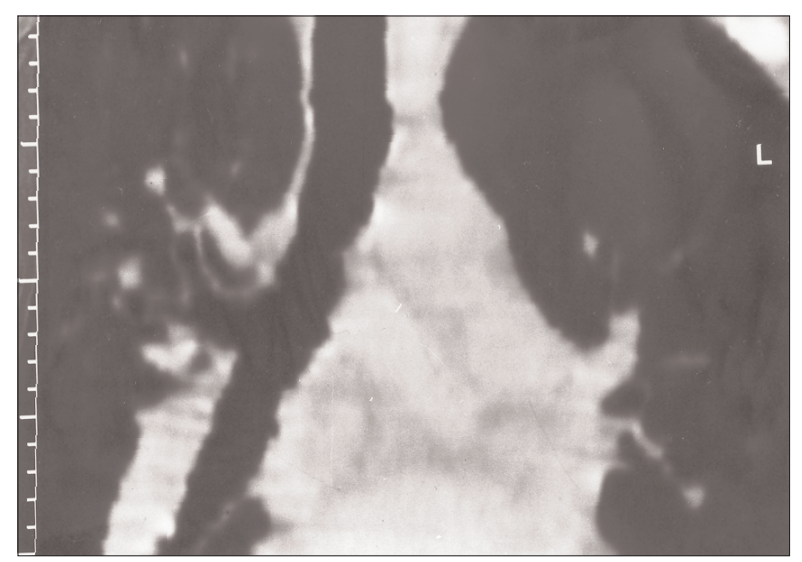

Fig. 2. - Computed tomography of the thorax (multi-planar reconstruction cross section) showing a mass narrowing left main bronchus, along a five centimeters part from main carina, homogeneous emphysema of the left lung and normal left upper lobe, lingual and lower lobe bronchi.

narrowing of the left main bronchi, five centimeters in length from the main carina (figure 2).

A fiberoptic bronchoscopy revealed millimetric polypoid lesions almost totally obstructing the left main bronchus, allowing inhalation but not exhalation of air. A histopathology of forceps biopsy showed monotonous cell infiltration which was formed by lymphocytes totally covering mucosa. Histopathology and immunhistochemistry ( CD20(+), CD43(+), CD23(-), CD10 $(-)$, CD5(-), CD3(-), cyclin D1(-) ) directed a diagnosis of stage-1, low grade MALT lymphoma (figure 3 and 4). The cranial and abdominal CT and the cytology of bone marrow aspiration were found to be normal.

The combination of doxorubicin $\left(50 \mathrm{mg} / \mathrm{m}^{2}\right)$, cyclofosfamide $\left(750 \mathrm{gr} / \mathrm{m}^{2}\right)$, vincristin (1.4 $\left.\mathrm{mg} / \mathrm{m}^{2}\right)$ and prednisone $(100 \mathrm{mg} /$ day, five days) with an interval of three weeks and a total of six cycles, was administered with no significant toxic effect.

After chemotherapy she had no further complaints and her physical exam and chest radiograph was normal. In a check up bronchoscopy the left main bronchus was not obstructed. In the spiral thorax CT an obstruction in the left main bronchi



Fig. 3. - (HE 10x20) Bronchoscopic biopsy showed subepitelial neoplastic lymphoid cells on bronchial mucosa.

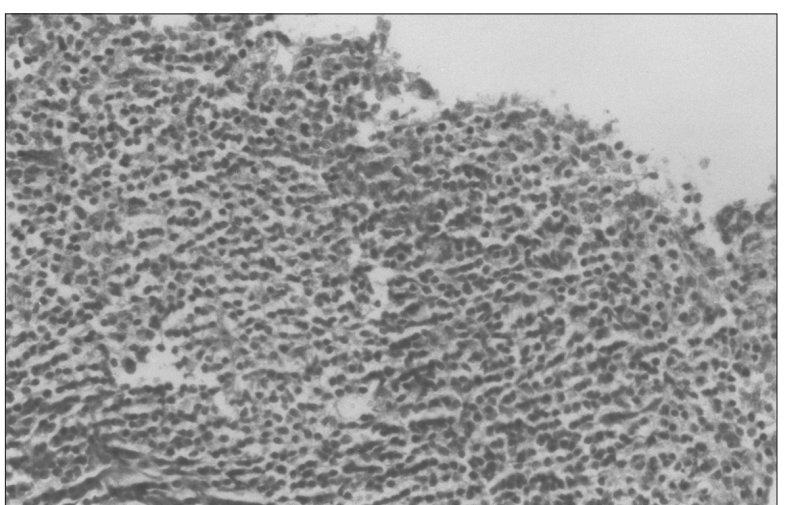

Fig. 4. - (HE 10x40) Bronchoscopic biopsy revealed neoplastic lymphoid cells with indefinite border and round nuclei.

was not seen and hypertranslucency of the left lung paranchima had disappeared totally. She has been followed now for three years without treatment.

\section{Discussion}

MALT lymphoma is a type of lymphoma which may involve many organs, usually causes pulmonary mass lesions and rarely goes without extrapulmonary involvement. Owing to a history of being treated and followed as bronchial asthma for one year, we would like to emphasise the importance of evaluating the patient's medical history, physical examination, chest $\mathrm{x}$-ray and spirometry together, especially in cases where the patient is suffering from breathlessness.

MALT in human lung is rare [5]. Histologically, MALT lymphomas have been characterised by a proliferation of neoplastic marginal zone-related cells which invade epithelial structures and form characteristic lymphoepithelial lesions. MALT lymphomas are low grade lymphomas, and histological progression from a low grade MALT lymphoma to a high grade lymphoma is rare, occurring in $<10 \%$ of cases [3].

BALT lymphomas can be seen between the years $25-85$, where is frequently seen in the sixth decade and affect both genders equally. The majority of patients are asymptomatic. Fever, weight loss, 
night sweats are the signs of extrathoracic disease or high grade lymphoma [4]. Having a localised lymphoma in the lung, our patient did not have systemic symptoms. She had suffered only from breathlessness for one year, and unfortunately, she had been given bronchodilator therapy without any diagnostic tests or definite diagnosis.

It is frequently impossible to differentiate MALT lymphoma and lung cancer radiologically. The most common radiological manifestations are pulmonary masses, or mass-like areas of consolidation and multiple pulmonary nodules. Common associated features include air bronchograms, a positive angiogram sign on contrast-enhanced CT, a halo of ground-glass shadowing or peribronchovascular thickening at tumour margins and discreet patches of ground-glass shadowing [4, 6, 7]. We found an interesting radiographic feature that might be a feature of many chest disorders affecting the left lung. There were transpositions of mediastinum and heart to the right side, volume increase and emphysema on the left lung. There was no consolidation or nodules which are the expected radiological features of the disease. The cause was obvious when the thorax spiral CT showed an endobronchial mass obstructing the left main bronchi.

Spirometry showed an obstructive pattern in patients with BALT lymphoma, where high grade lymphoma usually causes restrictive patterns [4]. Our patient having low grade MALT lymphoma had valve-type obstruction on the left main bronchi, total emphysema of the left lung and restrictive pattern in spirometry.

King et al [6]; reported one or more pulmonary masses or mass-like areas of lung consolidation as the most common $(87 \%)$ radiological appearances of 24 cases of low or high grade pulmonary MALT lymphoma. Pulmonary nodules were also common (75\%). The most common associated finding was the presence of an air bronchogram within pulmonary consolidation, masses or nodules seen in $88 \%$ of the patients. It is clear that the patient presented here, had a rare radiological feature, a mass almost totally obstructing the main bronchi. As the mass allowed inspiration to the left lung but not expiration, a valve-type obstruction occurred leading to emphysema of the left lung.

In half of the patients with pulmonary MALT lymphoma, bronchial stenosis and inflammation can be detected by fiberoptic bronchoscopy, and lymphomatoid infiltration of bronchial wall can be diagnosed using a transbronchial biopsy. Endoscopic examinations need to be performed on patients with lymphoma and clinical findings that suggest bronchial disease [4, 8, 9]. In King's series [6], 24 cases of pulmonary MALT lymphoma were diagnosed using surgical resection in nine patients, thoracoscopic or open lung biopsy in seven, bronchoscopic biopsy in three, post-mortem examination in three and percutaneous cutting needle biopsy in two. The diagnosis of our patient was made easier by using a bronchoscopic biopsy.

Tsukamoto $\mathrm{T}$ et al [10] reported a case presented with obstruction of the left upper lobe bronchus on CT and with endobronchial masses looked like a polypoid growth in the bronchial lumen at bronchoscopy. These masses almost completely obstructed the distal portion of the left upper lobe bronchus and partly obstructed the right upper lobe bronchus. Our case had millimetric polypoid lesions almost totally obstructing the left main bronchus, allowing inhalation but not exhalation of air. So the presence of a check valve-type obstruction on the left main bronchi explained the emphysema of the left lung.

MALT lymphoma cells typically surround reactive B-cell follicles in the distribution of the marginal zone and show a tendency to involve this zone when they disseminate to lymph nodes and spleen. The B-cells of MALT lymphoma share the cytological features and immunophenotype (CD20+, CD21+, CD35+, IgM+, IgD-) of marginal zone B-cells [2]. Immunophenotype leading to diagnosis of our patient was as follows: "CD20+, CD43+, CD23-, CD10-, CD5-, CD3-, cyclin D1-".

The prognosis depends on the dominant cell type and stage of the disease. A 5- and 10-year overall survival is $87 \%$ and $75 \%$ respectively, in stage-I and II of the disease. In stage-III and IV, the survival is about three years. The majority of the low grade MALT lymphomas have a slow course of disease and are usually localised at the time of diagnosis [2, 3]. In contrast, Thieblemont et al [3]; reported disseminating disease in 54 of 158 MALT lymphomas during the initial diagnosis, where there were only 15 patients who had only lung involvement. Similarly, the patient presented here, had both advantages of the low grade cytology and a single localization in lung without any extrapulmonary involvement.

In localised tumours surgery alone may result in cure. In symptomatic patients and if surgery is impossible, chemotherapy and radiotherapy may be preferred. With the possibility of recurrence locally or at the other extrapulmonary sites of MALT lymphoma, patients should be followed carefully. In addition a transformation from low grade to high grade lymphoma may be seen $[3,4]$. The presented patient had the combination chemotherapy alone, doxorubicin, cyclofosfamide, vincristin and prednisone, then she had a recovery of clinical, radiological and bronchoscopic findings.

Our case may have survey advantages because of the low grade cytology and single pulmonary involvement. Owing to a history of being treated and followed as bronchial asthma for one year, we would like to emphasise the importance of the evaluation of history, physical examination, chest-X-ray and spirometry together, especially in cases where the patient is suffering from breathlessness.

MALT lymphoma is a type of lymphoma which may involve many organs, usually causes pulmonary mass lesion and rarely goes without extrapulmonary involvement. Because of the probability of transformation from low to high grade and recurrence, patients should be followed carefully. 


\section{References}

1. Besien KV, Cabanillas F. Clinical manifestations, staging, and treatment of non-hodgkin lymphoma. In: Hoffman V, Benz EJ, Shattil SJ, Furie B, Cohen HJ, Silberstein LE, McGlave P, eds. Hematology Basic Principles and Practice. Churchill Livingstone, Philadelphia, 2000, pp. 1293-1339.

2. Cavalli F, Isaacson PG, Gascoyne RD, Zucca E. MALT lymphomas. Hematology 2001; 1: 241-258.

3. Thieblemont C, Berger F, Dumontet C, et al. Mucosaassociated lymphoid tissue lymphoma is a disseminated disease in one third of 158 patients analyzed. Blood 2000; 95: 802-806.

4. Salhany KE, Pietra GG. Lymphoproliferative and hematologic diseases involving the lung. In: Fishman AP, ed. Fishman's Pulmonary Diseases and Disorders. Mc. GrawHill Book Company, New York, 1998; pp. 1861-1879.

5. Wislez M, Cadranel J, Antoine M, et al. Lymphoma of pulmonary mucosa-associated lymphoid tissue: CT scan findings and pathological correlations. Eur Respir $J$ 1999; 14: 423-429.

6. King LJ, Padley SPG, Wotherspoon AC, Nicholson AG. Pulmonary MALT lymphoma: imaging findings in 24 cases. Eur Radiol 2000; 10: 1932-1938.

7. Mc Culloch GL, Sinnatamby R, Stewart S, Goddard M, Flower CDR. High resolution computed tomographic appearance of MALToma of the lung. Eur Radiol 1998; 8: 1669-1673.

8. Poletti V, Romagna M, Gasponi A, Baruzzi G, Allen KA. Bronchoalveolar lavage in the diagnosis of low grade, MALT type, B-cell lymphoma in the lung. Monaldi Arch Chest Dis 1995; 50: 191-194.

9. Garcia Clemente MM, Suarez Cuetara P, Roson Porto MC, Lopez Anglada JE, Gonzalez Martinez MB, Seco Garcia AJ. Bronchial-associated lymphoid tissue lymphoma. Arch Bronconeumol 2003; 39: 233-235.

10. Tsukamoto T, Satoh T, Yamada K, Nagasawa M. Endobronchial malignant lymphoma of mucosa-associated lymphoid tissue. Nihon Kyobu Shikkan Gakkai Zasshi 1996; 34: 253-258.

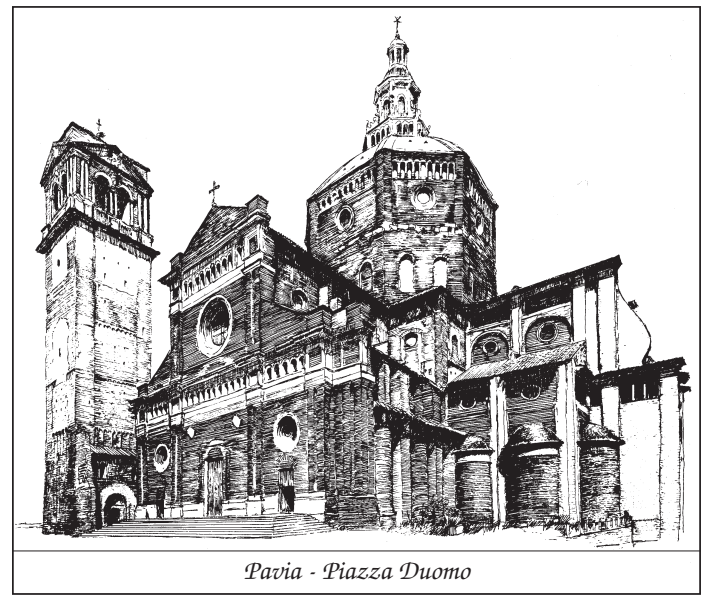

